Letras. LIma, Univ. San Marcos. 90: 66-70. 1986

\title{
Premisas para una historia de la Crítica de Arte en el Perú*
}

\author{
ALFONSO CASTRILLON VIZCARRA
}

Se puede decir, sin temor a equivocarnos, que la Crítica de Arte es una creación burguesa: Diderot, defensor del lacrimoso Greuze, era miembro de la burguesía pre-revolucionaria; Baudelaire, quien instaba a los burgueses para que dedicasen su tiempo a la formación de la sensibilidad, así como lo dedicaban con tanto empeño al florecimiento de sus negocios, también pertenecía a un sector de la burguesía, con especial interés en abrirse paso en un mercado todavía incipiente (1).

Pero nuestra afirmación no tendría valor si no agregaramos que la Crítica de Artepes ūna creación burguesa, porque estuvo desde el principio al servicio de los ideąles de clase de quienes la practicaron. En el caso de Diderot, gsu concepeión (deh "arte como moral" significará el requerimiento de una nueva sensibilidad contratia al "arte como placer" preconizado por los aristocráticos Boucher o Fragonard. Y en el caso de Baudelaire, la cvidente publicidad a favor del Romanticismo para tratar de imponerlo en esa clase que era "la mayoría -número e inteligencia - por lo tanto la fuerza, que es la justicia” (2).

Así pues, la crítica de Arte se practicó para sllos, para enseñarles qué era el arte y de paso, para que aprendieran .l comprar: he aquí dos aspectos fundamentales de la crítica de Arte que no pueden diso-

- El presente es el artículo introductorio a la "Historio de la crítica de arte en Lima" y precede a "La critica de los dilatantes". En: Revista de la Universidad Católica, Nueva Serie, No. 8, 1980, p. 81 y "Teófilo Costillo o la institución de la crítica" en Hneso Húmero, No. 9, p. 58, 1981.

(1) Diderot, Sur l'art ế les artistes. Textes réunis et présentés par Jean Seznec. Hartman, Paris 1967. También: Ernst Fischer, La necesidad del arfe. Ediciones Península, 2a. edición, 1970, p. 82.

(2) Baudelaire, Charles. Curiosités esthétiques. Edition Lamaitre, Garnler, París, 1962, p. 97. 
ciarse, ni sosloyarse por cierto afán purista. La diciáctica forma parte de la normal manera de reproducción del sistema ideológico y la compra-venta, del sistema artístico, tan importante como la producción. Al respecto J. C. Mariátegui ha dado luces sobre el problema en el "Artista y la época" (3). Si "La élite de la sociedad aristocrática, tenía más educación artística y más aptitud estítica que la élite de la sociedad burguesa", se entiende que la serzunda necesite de un especialista que lo guíe e instruya: de ahí el papel fundador de críticos como Diderot y Baudelaire. Pero es necesario que centremos nuestra atención en el próblema de la crítica, antes que en el demasiado particular y subjetivo de su productor. ¿Qué es la Crítica?

En un principio la Crítica de Arte se confundió con la habilidad de reconocer la bondad de una obra, incluyendo su autenticidad. Así lo dio a entender J. Richardson en su "Arte de criticar en materia de pintura" (4). Más adelante se identifica con ei "juicio" sobre las obras de arte, que de Kant en adelante se entenderá como límite de la razón, sabet distinguir y valorar. "El problesna de la crítica de arte es pues el de la capacidad y posibilidad de un cierto tipo de juicio: el juicio de gusto, es decir el apreciamiento del modo de sentir la obra de arte (...) históricamente, es decir en relación con su tiempo" (4).

Para Kant el juicio de gusto es un juicio sintético a priori, pero "La belleza que afirma a priori el juicio estético, carece de objeto real para el concepto correspondiente; si lo tuviera, se tiatāía de un juicio lógico y el esfuerzo de Kant se encamina a dejar bien sentado que el juicio estético no es juicio de conocimiento. No hay, por lo tanto, criterio objetivo y universal de la belleza, ni tampoco reglas del gusto. No hay ciencia de to bello, sino solamente crítica" (5).

Esta relatividad del Guticio estético tan claramente demostrada por el filósofo alemán, tuvo sin embargo poca influencia en la crítica posterior, por lo menos del Necoclasicismo hasta el surginiento de las vanguardias modernas (Impresionismo, Expresionismo, cubismo, etc.). A partir de ellas y de la relatividad física einsteniana, que servirá de marco para todas las otras relatividades de nuestro siglo (moral, polítíca, etc.), se romperán los criterios demasiado estrechos de las estéticas normativas producidas en las Academias de arte del siglo XIX.

La Crítica de Arte, como género literario, pertenece al ensayo, ya que no se propone comprobar hipótesis, a la manera científica, sino proporcionar juicios de gusto, relativos y teñidos de la sensibilidad del escritor. En cambio, la Historia de la Crítica de Arte, que es la

(3) Mariátegui, José Carlos. El artiste y lo época. Obros completas, Empreso Amauto, vol. 6, p. 15. p. 135.

(4) Grassi, Luigi. Dizionario dello critico d'arte. UTET, 1978, vol. 1,

(5) Lafuente-Ferrori, Enrique. Lo fundamentación y los problemos de la Historio del arto. Editoriol Tecnos, Madrid, 1951. 
que abordaremos, pertenece a la rama de la Hist rria de las Ideas. ¿Cuál es la materia de esta historia? Las ideas son los "hechos" de esta ciencia fáctica, y más particularmente las ideas estéticas. ¿̨Es posible dar cuenta de ellas, organizarlas e interpretarlas?

Pienso que es importante explicar, a estas alturas, cuáles son los fundamentos epistemológicos de una investigación que pretenda absolver tales preguntas. No radicará, como podrá suponerse, en probar o no que las ideas existen, sino de ver cómo se han constituido en conocimientos válidos o, según Cardoso, "cóms sc pasa de estados de menor conocimiento a los de un conocimiento más avanzado" (6).

Para no extendernos en discusiones que exceden los límites de este trabajo, debemos adelantar que, en relación al problema de si "las formas de conocimiento pertenecen al sujeto, al objeto o a algún tipo de erlación entre ambos" (7) suscribimos el modelo "pistemológice "interactivista" que "atribuye un papel activo al sujeto que a su vez está sometido a condicionamientos diversos, en particular a determinismos sociales, que introducen en el conocimiento una visión de la realidad transmitida socialmente" (8). Las ideas -y precisamente las estéticas- no surgen de una idealidad extraña al ejercicio social del hombre, sino como produeto del trabajo de éste "socio-históricamente determinado" (9).

Esta precisión es importante, porque aclara la opinión que suscribimos en dos puntos fundamentales: a) El arte no es un fenómeno surgido de la individualidad autoformativa, ni es "esencialmente espiritual" como se repite todavía; b) pero tampoco es urıa mera representación ideológica de los conflictos ocurridos en las reliciones de producción", error quebhå trenidod cenitiendaslos "realistas socialistas" (10).

Para vencer estas dificultades teoricas conviene volver a la formulación de que "lo que corresponde es vincular las cbras con sus propias condiciones materiales de producción", como bien ha dicho Gat cía Canclíni y Mirko Lauer puntualiza al dar los lineamientos de una Teoría social del arte, "es decir, una teoría que busque la concresión de la plástica no en la apariencia física del objeto, sino en las determinaciones de una existencia social como producción-distribución-consumo" (11).

(6) Cardoso, Ciro. Ineroducción al trabajo de la investigación Hisfórica. Grijalbo, Barcelono, 1981, p. 17.

(7) Ibidem, p. 23.

(8) Schaff, Adam. Historia y verdad. Grijalbo, México, 1974, p. 86.

(9) Cardoso, Ciro. Op. cit. p. 26.

(10) García Canclini, Néstor. Arte popular y sociedad en América, Grijalbo, México, 1977 , p. 35.

(11) Ibidem, p. 38-39. También: Mirko Lauer, "Critica de la artesania". Desco, 1982, p. 10. 
Las ideas estéticas surgen de las determinaciones de la existencia social de las obras y no de una región incontaminada c ideal como propugnan los idealistas académicos. Sin embargo iste marco teórico quedaría incompleto si no tuvieramos presente el factor ideológico de clase, como condicionante en la emisión de ideas.

La práctica demuestra que la división de clases se da en las relaciones dè producción: quienesi son dueños de los miedios de producción y quienes no lo son. Todos sabemos que estas relaciones son conflictivas. "Se trata, por ejemplo, de la contradicción entre las prácticas que tienden a la realización del provecho y las que tienden al aumento de salarios (lucha económica), entre las que tienden al mantenimiento de las relaciones sociales existentes y las que tienden a su transformación (lucha política), entre las que tienden a hacer aceptàr el "modo de vida" existente y las que tienden a su transformación (lucha ideológica)" (12).

El factor ideológico está presente desde el momento que la clase dominante, poseedora de los medios de producción, difunde y propicia ciertas ideas que sirven para reforzar el aparato económico-político. Dentro de estos factores reproductivos estín las ideas estéticas que generan formas artísticas determinadas en vista a representar los ideales de clase.

Estas incursiones en la Teoría Social del Arte erân necesarias para entender el sentido que adquiere el propósito de hacer una Historia de la Crítica de Arte en el Perú. Bajo las picrnisas anteriormente enunciadas, cabe pues formular nuestras hipótesis generales. En el Perú:

a) Cada clase modela su ideologia estética de acuerdo a los factores económicos y políticos que le dan su carácter.

b) La clase dominante ha impuesto sus criterios estéticos por medio de la crítica a través de diarios, revistas y libros, apoyada por las galerías y museos de arte.

c) La cultura dominante se ha caracterizado pos ejercer una crítica de arte de premisas "universales", por io tanto foráneas, fiel reflejo de la situación de mercado de otras latitudes.

d) Ha existido y existe una crítica consciente de nuestra condición de países dependientes, tanto económicamente cumo ideológicamente, que se expresa en otros términos y propugna una cultura liberadora.

Así pues la metodología de esta investigación se ha ido adaptando en relación a la necesidad de verificat las hipótesis planteadas. Era imprescindible un trabajo pormenorizado sobre las fuentes escri-

(12) Adjinicolou, Nikos. Historia del Arte y lucha de closes. Siglo XXI, 1974 , p. 10. 
tas en libros, diarios y revistas. Había que reunir y ordenar por primera vez, una cuantiosa bibliografía sobre la crítica de arte en el Perú. Cabría puntualizar que se ha puesto especial cuidado en seleccionar el material de acuerdo a su contenido. Se han tenido en cuenta artículos en los que se ve claramente la opinión crítica del autor, donde se advierte alguna tésis o adhesión a algún novimiento artístico, textos en suma, que remiten a la ideología estética del grupo social de quienes los escribieron. Por eso se ha scparado las simples notas informativas de exposiciones cuando no sirven para contextualizar la crítica. Sin embargo, ¿cómo escoger los aittores, cómo seleccionar sus artículos, sin caer en arbitrariedad? Toda historia es arbitraria y no seremos nosotros los que suscribamos la falacia de una historia objetiva. Por otro lado no creemos en cl carácter absoluto de nuestras verificaciones. Las ciencias fácticas se distinguen de las formales precisamente por el carácter de la verificación que es siempre incompleta y temporaria (13), lo que hace del historiador un hombre de su momento, susceptible o no a las corrientes ideológicas que echan a andar una sociedad y en este sentido io queda más que una alternativa: caminar con ella para no convertirse en piedra.

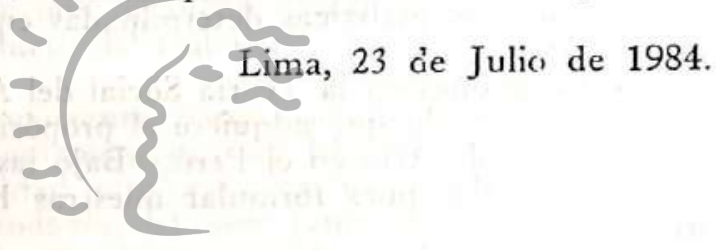

\section{Biblioteca de Letras "Jorge Puccinelli Converso"}

(13) Bunge, Mario. La ciencia, su método y su filosofia. Siglo Veinte, Buenos Aires, 1973. 